\title{
Does surgical approach influence mid- to long-term patient-reported outcomes after primary total hip replacement? A comparison of the 3 main surgical approaches
}

\author{
Romain Galmiche, MD \\ Stéphane Poitras, PT, PhD \\ Johanna Dobransky, MHK \\ Paul R. Kim, MD \\ Robert J. Feibel, MD \\ Wade Gofton, MD \\ Hesham Abdelbary, MD \\ Paul E. Beaulé, MD
}

Accepted Aug. 30, 2019

\section{Correspondence to: P. Beaulé \\ Ottawa Hospital - General Campus 501 Smyth Rd, Box 502, Rm W1646 Ottawa ON K1H 8 L6 \\ pbeaule@ottawahospital.on.ca}

DOI: $10.1503 /$ cjs.008919

\begin{abstract}
Background: The most effective surgical approach to total hip replacement (THR) remains controversial. Most studies that have compared approaches have reported only short-term outcome data. It is therefore unclear in the literature if a particular surgical approach offers long-term advantages. The aim of this study was to determine the effect of the 3 main surgical approaches to THR on patient-reported outcomes 5 years after surgery.
\end{abstract}

Methods: All patients who underwent a THR for osteoarthritis or osteonecrosis between 2008 and 2012 by an anterior, posterior or lateral approach at The Ottawa Hospital in Ontario, Canada, were included in the study. All preoperative and postoperative scores for the Hip Disability and Osteoarthritis Outcome Score (HOOS) and Western Ontario and MacMaster Universities Osteoarthritis Index (WOMAC) questionnaires were recorded. Analysis of covariance was used to study the relationship between the amount of change in scores on the HOOS and WOMAC subscales (dependent variables) and the surgical approach. The confounding factors of age, sex, American Society of Anesthesiologists (ASA) class, Charnley classification and body mass index were included in the analysis.

Results: There were 138 patients $(37.6 \%)$ in the posterior approach group, $104(28.3 \%)$ in the lateral approach group and $125(34.1 \%)$ in the anterior approach group. There were no significant differences among the 3 groups in terms of Charnley classification, body mass index, sex, ASA class, surgical side and preoperative functional scores. We did not observe any significant differences in the amount of change in the scores for HOOS and WOMAC subscales among the 3 groups. There were also no differences in the final postoperative scores.

Conclusion: Our findings suggest that the choice of surgical approach in primary THR surgery without revision has no influence on functional outcomes and quality of life after 5 years. Further studies are needed to assess how patient age and sex may influence the functional outcome of individual surgical approaches.

Contexte : L'approche chirurgicale la plus efficace pour l'arthroplastie totale de la hanche (ATH) n'a pas été déterminée. La plupart des études qui ont comparé les différentes approches n'ont fait état que de données à court terme. Donc, la littérature nous renseigne peu sur leurs bienfaits à long terme. Le but de cette étude est de vérifier l'effet des 3 principales approches chirurgicales pour l'ATH sur les paramètres rapportés par les patients 5 ans après la chirurgie.

Méthodes : Tous les patients soumis à une ATH pour arthrose ou ostéonécrose entre 2008 et 2012 par approche antérieure, postérieure ou latérale à l'Hôpital d'Ottawa, en Ontario, au Canada, ont été inclus dans l'étude; et tous les scores préopératoires et postopératoires des questionnaires HOOS (Hip Disability and Osteoarthritis Outcome Score) et WOMAC (Western Ontario and MacMaster Universities Osteoarthritis Index) ont été enregistrés. L'analyse de covariance a servi à étudier le lien entre l'ampleur des changements aux scores des sous-échelles HOOS et WOMAC (variables dépendantes) et l'approche chirurgicale. L'analyse a aussi tenu compte de facteurs de confusion tels que l'âge, le sexe, la classe ASA (American Society of Anesthesiologists), classification de Charnley et indice de masse corporelle.

Résultats : Le groupe soumis à l'approche postérieure comptait 138 patients $(37,6 \%)$, à l'approche latérale $104(28,3 \%)$ et à l'approche antérieure $125(34,1 \%)$. Il n'y avait pas de différences significatives entre les 3 groupes aux plans de la classification de Charnley, de l'indice de masse corporelle, du sexe, de la classe ASA, du côté où la chirurgie a été effectuée et des paramètres fonctionnels préopératoires. Nous n'avons observé aucune différence significative quant à l'ampleur du changement aux scores des sous-échelles HOOS et WOMAC entre les 3 groupes; il en est allé de même pour les scores postopératoires finaux.

Conclusion : Selon nos observations, le choix de l'approche chirurgicale pour l'ATH primaire sans révision n'exerce aucune influence sur les paramètres fonctionnels et la qualité de vie après 5 ans. Il faudra procéder à d'autres études pour évaluer l'influence potentielle de l'âge et du sexe sur les paramètres fonctionnels des différentes approches. 
$\mathrm{T}$ otal hip replacement (THR) has become one of the most commonly performed orthopedic surgical procedures, and levels of patient satisfaction are generally high. ${ }^{1}$ Nevertheless, some controversy still exists regarding the choice of surgical approach to optimize patient function and avoid complications, such as dislocation. Although the posterior and lateral approaches have been the most commonly performed approaches in the last decade, ${ }^{2}$ there has been a growing interest in the anterior approach, which is now being used by $30 \%$ of surgeons in North America. ${ }^{3}$ It is clear from the literature that each approach has advantages and disadvantages with respect to risk of dislocation, ${ }^{4-6}$ paresthesias, ${ }^{7-9}$ perioperative fractures ${ }^{10,11}$ and early function. ${ }^{12-14}$ However, most of the clinical reports published to date have focused on comparing the short-term outcomes of the anterior and posterior approaches, ${ }^{12}$ with functional differences attenuating over time..$^{15}$

There has been little research comparing the mid- to long-term outcomes of the 3 main surgical approaches to THR (lateral, anterior, posterior). This is especially relevant as implant-related failures are unlikely to occur before the 15 -year mark. ${ }^{16}$ As such, it is imperative to understand how choice of surgical approach may influence long-term patientreported outcomes and quality of life. Even more importantly, with government funding agencies placing a growing emphasis on the provision of high-quality care, institutions are now being asked to collect data on patient-reported outcomes as a condition of funding. ${ }^{17,18}$ Consequently, it is important to report on the expected patient-reported outcomes of THR as a function of surgical approach. The primary aim of this study was to determine if the surgical approach affects long-term patient-reported outcomes for patients with a well-functioning primary THR.

\section{Methods}

This was a retrospective review of prospectively collected data for THR performed by arthroplasty surgeons at a large tertiary care institution in Ontario, Canada. All primary THRs performed between 2008 and 2012 were queried from the database of The Ottawa Hospital. Patients who had a primary diagnosis of degenerative arthritis or osteonecrosis and who completed the Hip Disability and Osteoarthritis Outcome Score (HOOS) questionnaire and the Western Ontario and MacMaster Universities Osteoarthritis Index (WOMAC) at the preoperative and 5-year postoperative time points were included. Given the volume of cases done annually and the cumulative accumulation of cases, in 2010 we moved to randomly sampling 1 of every 5 patients who completed the preoperative questionnaires for completion of the follow-up questionnaires after surgery. Our exclusion criteria were previous hip surgery, history of infection, a reoperation, rheumatoid arthritis and posttraumatic arthritis. Seven high-volume surgeons performed the procedures on the patients in the study cohort. In our department, surgeons usually perform the approach with which they are most comfortable, even if in some cases they could have chosen a different surgical approach for reasons that are difficult to describe in a retrospective study.

\section{Description of surgical approaches}

With the modified lateral or Hardinge approach, the patient was in the lateral decubitus position. The iliotibial band was split in line with the skin incision, and the anterior one-third of the fibres of the gluteus medius and gluteus minimus were reflected anteriorly, exposing the femoral neck and anterior join capsule. Capsulectomy was performed anteriorly and superiorly. The abductors were then repaired with nonabsorbable heavy sutures. Patients were allowed to weight bear as tolerated with assistive devices.

With the anterior approach, the patient was in the supine position on either a positioning or a regular table. ${ }^{19}$ A single straight incision was performed $2 \mathrm{~cm}$ lateral to the anterior superior iliac spine and centred over the greater trochanter. The incision was then developed in the superior gluteal-femoral internervous path, with dissection occurring within the tensor fascia sheath. The fascia over the rectus femoris was released and the rectus femoris was mobilized medially. The reflected part of the rectus femoris was partially released and a lateral capsulectomy was then performed. Subsequently, the femoral neck cut was done in situ and the leg was externally rotated to permit excision of the femoral head. To facilitate mobilization of the femur, the capsule was released for the inferomedial calcar. The piriformis was not released as a general rule, but the obturator internus and externus were. However, we were not able to confirm this without a doubt because of the retrospective nature of the study. The release of the capsule could have led to a piriformis section in some cases.

For the posterior approach, the iliotibial band was split in line with the gluteus maximus muscle. The short external rotators (piriformis, gemelli and obturator externus) were released and tagged for intraosseous repair at the end of the surgery. The gluteus maximus sling was not released.

\section{Statistical analysis}

The final patient sample was compared with the entire population using $t$ tests and $\chi^{2}$ analyses to determine its representativeness for age, sex, surgery side, body mass index (BMI), American Society of Anesthesiologists (ASA) class and approach. We also analyzed the representativeness of the preoperative scores for patient-reported outcome measures (PROMs) for patients in the final 
sample compared with those of all patients who had preoperative PROM scores. The characteristics of patients in the final sample were also compared between approaches with analysis of variance and $\chi^{2}$ analyses. Analysis of covariance (ANCOVA) was used to study the relationship between the amount of change in scores for the HOOS, WOMAC and 12-item Short Form Health Survey (SF-12) subscales (dependent variables) and the approach used, by also including the confounding factors of age, sex, ASA score, Charnley score and BMI. ANCOVAs were performed for each PROM subscale. Using a priori ANCOVA fixed effects to detect a moderate effect size of 0.25 between the 3 approaches with 5 covariates, with an $\alpha$ of 0.05 and a $\beta$ of 0.95 , we determined that a sample of at least 210 patients was needed. A $p$ value of 0.05 was used for the level of significance in all analyses. The power calculation was performed in $G^{*}$ Power version 3.1.9.2 (Universität Düsseldorf), and SPSS version 24.0 (IBM) was used for all statistical analyses.

\section{Results}

The study flow chart is presented in Figure 1. A total of 1895 patients underwent a primary THR for degenerative osteoarthritis or osteonecrosis during the study period. Among these patients, 369 (19.5\%) had PROM scores for the preoperative and 5 -year postoperative time points. Two patients were further excluded because they underwent subsequent surgeries ( 1 neck fracture of a modular stem among the patients who underwent the anterior approach and an aseptic loosening of the acetabular cup among the posterior group), leaving us with 367 patients in the final sample: 138 patients $(37.6 \%)$ in the posterior group, $104(28.3 \%)$ in the lateral group and $125(34.1 \%)$ in the anterior group. The characteristics of the entire THR population and the final sample of patients are described in Table 1. There were no significant differences between the whole THR population and the final sample in terms of sex, surgery side and BMI. However, patients in the final sample were younger and were in better physical health (as measured by ASA class) than the whole population. Patients in the final sample had significantly less pain and better functional scores than patients who completed only preoperative PROMs (Table 1), but the differences were under the minimal detectable change for these instruments. ${ }^{17,18}$

The mean follow-up for the study cohort was 5.3 years (range 5-7 yr): 277 patients at 5 years, 63 patients at 6 years and 27 patients at 7 years. The 3 groups were contemporaneous. Table 2 summarizes the demographic data for the 3 surgical approaches. Age was the only variable that differed significantly among the groups, with patients who received the anterior approach being younger. The preoperative PROM scores, health status (according to the Charnley classification), BMI and ASA class did not differ $(p<0.05)$.

For the covariates, only ASA class was significantly associated with the change in all PROM scores (except the scores for the mental component of the SF-12 instrument $)(p<0.05)$. Sex was

Fig. 1. Study flow chart. PROMs = patient-reported outcome measures; THR = total hip replacement. 
associated with 3 outcomes (WOMAC pain, $p=0.014$; WOMAC function/HOOS activities of daily living, $p=$ 0.019 ; HOOS pain, $p=0.032)$. Age was associated with 2 outcomes (WOMAC pain, $p=0.029$; HOOS symptoms, $p=0.022)$. BMI and Charnley score were not associated with any outcome changes $(p>0.05)$. The improvement in scores was excellent among the 3 groups, with a minimum improvement of $115 \%$ for the pain HOOS subscale and improvement of up to $254 \%$ for the HOOS hip-related quality of life subscale. We did not observe any significant differences in the amount of change in scores on the HOOS and WOMAC subscales among the groups, controlling for any confounding factors. There was also no difference in the postoperative final scores on the HOOS and WOMAC subscales among the 3 groups, again controlling for confounding factors (Table 3). There was a tendency, which was not statistically significant, for patients who underwent the lateral approach to have more improvements in their preoperative symptoms $(p=0.06)$ and in their scores on the SF-12 mental subscale $(p=0.053)$.

\section{Discussion}

The benefits of THR in terms of functional improvement are excellent, and this orthopedic intervention has improved the lives of millions of patients worldwide..$^{20} \mathrm{It}$ is associated with excellent short- and long-term patientreported outcomes. These results have been achieved through tremendous advances in preventing infection, improving the durability of biomaterials and designing implants that optimize biomechanics. ${ }^{21}$ Another key to the success of THR in terms of minimizing recovery time and improving patient function is the choice of surgical approach. This is especially relevant in the past decade, where patient expectations and the influence of surgical approach on short-term outcomes and speed of recovery have been a strong focus. ${ }^{22}$ Nevertheless, studies looking at the impact of surgical approach on mid- to long-term functional outcomes are limited (Table 4). ${ }^{15,23-27}$ Our single-centre observational study shows that the anterior, lateral and posterior surgical approaches provide comparable improvements in scores on PROMs at long-term follow-up.

When surgeons decide on the optimal surgical intervention for a given patient, they understand that any surgical approach to the hip carries an inherent risk of damaging the soft tissue envelope (gluteus maximus and external rotators for the posterior approach, abductor muscles for the lateral approach and tensor muscle for the anterior approach), ${ }^{28}$ which can affect function and long-term

Table 1. Characteristics of study patients and preoperative scores for patient-reported outcome measures

No. (\%) of patients who underwent THR in 2008-2012*

\begin{tabular}{|c|c|c|c|c|}
\hline & & & & \multirow[b]{3}{*}{$p$ value } \\
\hline & All patients & $\begin{array}{l}\text { Patients who completed } \\
\text { preoperative PROMs }\end{array}$ & $\begin{array}{l}\text { Patients who completed both } \\
\text { preoperative and postoperative } \\
\text { PROMs }\end{array}$ & \\
\hline Characteristic or score & $n=1895$ & $n=878$ & $n=367$ & \\
\hline Age, mean $\pm S D$ & $65.16 \pm 12.00$ & - & $63.65 \pm 10.26$ & 0.003 \\
\hline Sex (male) & 805 (42.5) & - & $160(43.6)$ & 0.79 \\
\hline Side (left) & 919 (48.5) & - & 167 (45.5) & 0.20 \\
\hline $\mathrm{BMI}$, mean $\pm \mathrm{SD}$ & $29.25 \pm 6.21$ & - & $28.80 \pm 5.74$ & 0.10 \\
\hline \multicolumn{5}{|l|}{ ASA class } \\
\hline 1 & $77(4.1)$ & - & $29(7.9)$ & $<0.001$ \\
\hline II & 934 (49.3) & - & 205 (55.9) & - \\
\hline III & $854(45.1)$ & - & $131(35.7)$ & - \\
\hline IV & $30(1.6)$ & - & $2(0.50)$ & - \\
\hline \multicolumn{5}{|l|}{ Approach } \\
\hline Anterior & $456(24.1)$ & - & $125(34.1)$ & $<0.001$ \\
\hline Posterior & $833(44.0)$ & - & $138(37.6)$ & - \\
\hline Lateral & $606(32.0)$ & - & $104(28.3)$ & - \\
\hline \multicolumn{5}{|c|}{ Preoperative WOMAC score, mean \pm SD } \\
\hline Pain & - & $44.26 \pm 17.48$ & $46.37 \pm 16.98$ & 0.002 \\
\hline Function & - & $39.70 \pm 17.74$ & $42.12 \pm 17.10$ & 0.001 \\
\hline \multicolumn{5}{|l|}{ Preoperative HOOS score, mean \pm SD } \\
\hline Pain & - & $38.44 \pm 16.22$ & $40.49 \pm 15.73$ & 0.002 \\
\hline Symptoms & - & $40.04 \pm 17.93$ & $40.46 \pm 17.43$ & 0.53 \\
\hline Sports and recreational function & - & $22.80 \pm 22.32$ & $23.44 \pm 21.46$ & 0.48 \\
\hline Hip-related quality of life & - & $21.07 \pm 16.61$ & $22.82 \pm 16.74$ & 0.009 \\
\hline
\end{tabular}




\begin{tabular}{|c|c|c|c|c|}
\hline \multirow[b]{2}{*}{ Characteristic or score } & \multicolumn{3}{|c|}{ No. (\%) of patients; ${ }^{*}$ surgical approach } & \multirow[b]{2}{*}{$p$ value } \\
\hline & $\begin{array}{l}\text { Anterior } \\
n=125\end{array}$ & $\begin{array}{c}\text { Posterior } \\
n=138\end{array}$ & $\begin{array}{l}\text { Lateral } \\
n=104\end{array}$ & \\
\hline Age, mean $\pm S D$ & $59.57 \pm 9.00$ & $64.54 \pm 10.97$ & $67.26 \pm 9.10$ & $<0.001$ \\
\hline ASA class & & & & 0.11 \\
\hline 1 & 16 (12.8) & $9(6.5)$ & $4(3.8)$ & \\
\hline II & $69(55.2)$ & $78(56.6)$ & $56(53.8)$ & \\
\hline III & $40(32.0)$ & $51(37.0)$ & $43(41.3)$ & \\
\hline IV & $0(0)$ & $0(0)$ & $1(1.0)$ & \\
\hline Sex (male) & 49 (39.2) & $70(50.7)$ & $42(40.4)$ & 0.12 \\
\hline $\mathrm{BMI}$, mean $\pm \mathrm{SD}$ & $27.91 \pm 4.99$ & $29.38 \pm 5.49$ & $29.12 \pm 6.62$ & 0.09 \\
\hline Side (left) & $60(48.0)$ & $60(43.5)$ & $48(46.2)$ & 0.76 \\
\hline Charnley class & & & & 0.89 \\
\hline A & 52 (41.6) & $62(44.9)$ & $46(44.2)$ & \\
\hline B & $22(17.6)$ & $18(13.0)$ & $16(15.4)$ & \\
\hline C & $51(40.8)$ & $58(42.0)$ & $42(40.4)$ & \\
\hline \multicolumn{5}{|l|}{ Preoperative HOOS score, mean \pm SD } \\
\hline Pain & $40.86 \pm 15.03$ & $41.18 \pm 17.24$ & $39.12 \pm 14.52$ & 0.58 \\
\hline Hip-related quality of life & $21.57 \pm 4.96$ & $24.77 \pm 19.56$ & $21.78 \pm 14.54$ & 0.24 \\
\hline Symptoms & $40.14 \pm 15.98$ & $42.48 \pm 18.78$ & $38.21 \pm 17.16$ & 0.17 \\
\hline Sports and recreational function & $23.27 \pm 21.21$ & $25.95 \pm 24.01$ & $20.33 \pm 17.62$ & 0.14 \\
\hline Pain & $46.40 \pm 16.80$ & $47.12 \pm 18.09$ & $45.34 \pm 15.75$ & 0.72 \\
\hline $\begin{array}{l}\text { Preoperative WOMAC function score / } \\
\text { HOOS ADL score, mean } \pm \text { SD }\end{array}$ & $43.21 \pm 16.33$ & $43.10 \pm 18.07$ & $39.52 \pm 16.62$ & 0.19 \\
\hline \multicolumn{5}{|l|}{ SF-12 } \\
\hline Mental & $51.76 \pm 12.82$ & $51.78 \pm 13.13$ & $48.92 \pm 11.56$ & 0.17 \\
\hline Physical & $31.55 \pm 8.22$ & $30.22 \pm 8.66$ & $29.03 \pm 7.01$ & 0.07 \\
\hline
\end{tabular}

by others. Finally, although PROMs are among the key performance indicators for joint arthroplasty, there is evidence that from a biomechanical standpoint, for instance as seen in gait studies, ${ }^{30,31}$ surgical approaches do differ, which may explain why in the short term some approaches may be associated with more rapid recovery, ${ }^{32,33}$ with the differences attenuating over time. ${ }^{34}$

One possible explanation for the equivalence of patientreported outcomes among our 3 groups is that early functional differences level off with rehabilitation in the first year, and differences are further minimized among patients of increasing age, who tend to have lower activity levels. Recent biomechanical gait studies found that surgical approach did not affect the outcomes at 1 year postoperatively. ${ }^{35}$ However, the impact of the surgical approach on the early outcomes is probably influenced by several factors, such as preoperative muscle function and

outcomes in a negative way. Our results suggest that the 3 approaches can effectively provide patients with similar levels of pain relief and similar quality of life.

This is consistent with some studies on mid- to longterm outcomes that have usually compared 2 approaches (Table 4). Palan and colleagues ${ }^{23}$ performed a single-centre study and found no significant differences at 5 years between the posterior and anterior approaches. Our study was also based on data from a single centre, which ensured some homogeneity in regard to the clinical pathways for each approach. This may explain why we also did not find differences when we compared the lateral approach with the anterior or posterior approach. Conversely, a Swedish Hip Arthroplasty Register study ${ }^{29}$ found that the posterior approach provided better pain relief and satisfaction than the lateral approach at both the 1-year and 6-year postoperative visits. However, these results could be explained by regional procedural differences not captured by registry data. Although the use of data from a single institution reduces the likelihood that procedure-related factors might explain differences in patient-related outcomes, it also limits the generalizability of study results; this highlights the importance of having our results corroborated subsequent damage at the time of surgery. Indeed, it has been shown that the abductor muscle impairment caused by the lateral approach can affect early outcomes. ${ }^{36}$ Furthermore, the patients who completed both preoperative and postoperative PROMs had significantly less pain and better functional scores at the preoperative time point than patients who only completed preoperative PROMs. Although there were statistically significant differences, they were not found to reach the level of minimal clinically important change, suggesting that the $p$ values need to be interpreted with caution. In addition, we do not fully understand the influence of patient age, sex and underlying diagnosis in regard to how surgical approach may affect health-related quality of life outcomes, with a recent study highlighting the finding that men and women do differ in terms of their gait recovery patterns. ${ }^{37}$ The outcomes associated with a given surgical approach could also be influenced by certain patient characteristics, such as $\mathrm{BMI}$ or preoperative gait biomechanics. ${ }^{38}$

Although it is difficult to specify which THR surgical approach is best, some patients could benefit more than others from any given surgical approach depending on their demographic characteristics. Older age and sex have 


\begin{tabular}{|c|c|c|c|c|c|}
\hline \multirow[b]{2}{*}{ Instrument; subscale } & \multirow[b]{2}{*}{ Measure } & \multicolumn{3}{|c|}{ Surgical approach } & \multirow[b]{2}{*}{$p$ value } \\
\hline & & Anterior & Posterior & Lateral & \\
\hline \multicolumn{6}{|l|}{ HOOS } \\
\hline \multirow[t]{3}{*}{ Pain } & $\begin{array}{l}\text { Amount of change in score; } \\
\text { mean } \pm S D\end{array}$ & $46.89 \pm 19.41$ & $47.61 \pm 23.32$ & $50.32 \pm 18.95$ & 0.20 \\
\hline & $\begin{array}{l}\text { Final score (absolute value), } \\
\text { mean } \pm \text { SD }\end{array}$ & $87.75 \pm 16.28$ & $88.79 \pm 14.95$ & $89.44 \pm 15.33$ & \\
\hline & $\%$ increase & 115 & 116 & 129 & \\
\hline \multirow[t]{3}{*}{$\begin{array}{l}\text { Hip-related quality of } \\
\text { life }\end{array}$} & $\begin{array}{l}\text { Amount of change in score, } \\
\text { mean } \pm \text { SD }\end{array}$ & $54.88 \pm 25.26$ & $53.46 \pm 29.31$ & $52.78 \pm 24.22$ & 0.85 \\
\hline & $\begin{array}{l}\text { Final score (absolute value), } \\
\text { mean } \pm \text { SD }\end{array}$ & $76.45 \pm 23.632$ & $78.23 \pm 21.85$ & $74.56 \pm 24.24$ & \\
\hline & $\%$ increase & 254 & 216 & 242 & \\
\hline \multirow[t]{3}{*}{ Symptoms } & $\begin{array}{l}\text { Amount of change in score, } \\
\text { mean } \pm S D\end{array}$ & $46.4 \pm 18.77$ & $44.94 \pm 22.76$ & $49.75 \pm 20.73$ & 0.06 \\
\hline & $\begin{array}{l}\text { Final score (absolute value), } \\
\text { mean } \pm \text { SD }\end{array}$ & $86.54 \pm 14.68$ & $87.42 \pm 14.47$ & $87.96 \pm 15.51$ & \\
\hline & $\%$ increase & 116 & 106 & 130 & \\
\hline \multirow[t]{3}{*}{$\begin{array}{l}\text { Sports and } \\
\text { recreational function }\end{array}$} & $\begin{array}{l}\text { Amount of change in score, } \\
\text { mean } \pm \text { SD }\end{array}$ & $55.68 \pm 30.09$ & $51.64 \pm 33.05$ & $50.55 \pm 33.73$ & 0.80 \\
\hline & $\begin{array}{l}\text { Final score (absolute value), } \\
\text { mean } \pm \text { SD }\end{array}$ & $78.95 \pm 24.50$ & $77.59 \pm 24.62$ & $70.88 \pm 30.47$ & \\
\hline & $\%$ increase & 239 & 199 & 249 & \\
\hline \multirow[t]{3}{*}{ WOMAC pain } & $\begin{array}{l}\text { Amount of change in score, } \\
\text { mean } \pm \text { SD }\end{array}$ & $43.47 \pm 19.35$ & $43.09 \pm 22.65$ & $45.72 \pm 18.53$ & 0.23 \\
\hline & $\begin{array}{l}\text { Final score (absolute value), } \\
\text { mean } \pm \text { SD }\end{array}$ & $89.87 \pm 15.05$ & $90.21 \pm 14.07$ & $91.05 \pm 13.84$ & \\
\hline & $\%$ increase & 94 & 91 & 100 & \\
\hline \multirow[t]{3}{*}{$\begin{array}{l}\text { WOMAC function / } \\
\text { HOOS ADL }\end{array}$} & $\begin{array}{l}\text { Amount of change in score, } \\
\text { mean } \pm \text { SD }\end{array}$ & $46.18 \pm 19.03$ & $44.62 \pm 22.82$ & $46.09 \pm 20.74$ & 0.83 \\
\hline & $\begin{array}{l}\text { Final score (absolute value), } \\
\text { mean } \pm \text { SD }\end{array}$ & $89.39 \pm 15.77$ & $87.72 \pm 15.99$ & $85.61 \pm 17.93$ & \\
\hline & $\%$ increase & 107 & 104 & 117 & \\
\hline \multicolumn{6}{|l|}{ SF-12 } \\
\hline \multirow[t]{3}{*}{ Mental } & $\begin{array}{l}\text { Amount of change in score, } \\
\text { mean } \pm \text { SD }\end{array}$ & $3.34 \pm 12.05$ & $2.37 \pm 11.73$ & $6.56 \pm 11.34$ & 0.05 \\
\hline & $\begin{array}{l}\text { Final score (absolute value), } \\
\text { mean } \pm \text { SD }\end{array}$ & $55.1 \pm 8.08$ & $54.15 \pm 9.68$ & $55.48 \pm 7.84$ & \\
\hline & $\%$ increase & 6 & 5 & 13 & \\
\hline \multirow[t]{3}{*}{ Physical } & $\begin{array}{l}\text { Amount of change in score, } \\
\text { mean } \pm \text { SD }\end{array}$ & $15.64 \pm 10.54$ & $13.65 \pm 12.18$ & $14.65 \pm 9.90$ & 0.52 \\
\hline & $\begin{array}{l}\text { Final score (absolute value), } \\
\text { mean } \pm \text { SD }\end{array}$ & $47.19 \pm 10.64$ & $43.87 \pm 11.22$ & $43.68 \pm 10.70$ & \\
\hline & $\%$ increase & 50 & 45 & 50 & \\
\hline
\end{tabular}

been shown to be associated with lower functional outcomes, as well as higher BMI. ${ }^{39,40}$ Furthermore, several studies have demonstrated that specific surgical approaches could lead to better outcomes for some subgroups of patients: Müller and colleagues ${ }^{41}$ suggested that a mini-invasive approach for patients who are older than 70 years and have a BMI over $25 \mathrm{~kg} / \mathrm{m}^{2}$ can reduce muscle atrophy and fatty infiltration and produce better outcomes. In addition, women do not have the same hip musculature as men $^{42}$ and use of a muscle-sparing approach should be considered for them. Little information is available in the literature on the role of bone geometry (fem- oral offset, acetabulum anteversion, neck-shaft angle) in the choice of surgical approach, even though some authors have highlighted the advantage of some approaches for specific pathologies, such as hip dysplasia. ${ }^{43}$ Unfortunately, because of the sample size in our study, we were not able to conduct subgroup analyses looking at the impact of surgical approach with respect to specific patient characteristics such as sex, age or BMI. Finally, the ceiling effect common to the PROMs could conceal some improvements when patients score well at baseline, which makes it more difficult to measure the effect of the THR as a treatment for osteoarthritis in some cases. ${ }^{44}$ 
Table 4. Literature published in the last 20 years assessing functional outcomes by surgical approach with a minimum of 1-year follow-up

\begin{tabular}{|c|c|c|c|c|c|}
\hline Study & Follow-up, yr & Approaches compared & No. of patients & Instrument(s) used & $\begin{array}{l}\text { Clinical results: approach } \\
\text { favoured }\end{array}$ \\
\hline \multirow[t]{2}{*}{ Palan et al. $2009^{23}$} & 5 & Posterior & 301 & Oxford Hip Score & No differences \\
\hline & & Anterolateral & 498 & & \\
\hline \multirow[t]{2}{*}{ Restrepo et al. $2010^{24}$} & 2 & Anterior & 50 & WOMAC, SF-36 & No differences \\
\hline & & Direct lateral & 50 & & \\
\hline \multirow[t]{2}{*}{ Smith et al. $2012^{25}$} & $1-3$ & Posterior & 665 & WOMAC & Posterior \\
\hline & & Anterolateral & 246 & & \\
\hline \multirow[t]{2}{*}{ Lindgren et al. $2014^{26}$} & 6 & Posterior & 3310 & EQ-5D & Posterior \\
\hline & & Direct lateral & 1652 & & \\
\hline \multirow[t]{2}{*}{ Reichert et al. $2015^{27}$} & $3.3-6.7$ & Minimally invasive anterior & 85 & HHS, UCLA, SF-36 & No differences \\
\hline & & Direct lateral & 86 & & \\
\hline \multirow[t]{2}{*}{ Araújo et al. $2017^{15}$} & 2 & Posterior & 46 & HOOS & No differences \\
\hline & & Anterolateral & 48 & & \\
\hline \multirow[t]{3}{*}{ Our study } & $5-7$ & Anterior & 125 & $\begin{array}{l}\text { WOMAC, HOOS, } \\
\text { SF-12 }\end{array}$ & No differences \\
\hline & & Direct lateral & 104 & & \\
\hline & & Posterior & 138 & & \\
\hline
\end{tabular}

\section{Limitations}

This study has several limitations. First, the results do not mean that every patient who undergoes a THR by any approach will have the same long-term outcomes. Other factors, including muscle atrophy and gait imbalances, which may be aggravated with particular surgical approaches, ${ }^{45}$ should be considered before a surgical approach is chosen. Unfortunately, our study and the current literature are still unable to address this interesting concern. In addition, we excluded patients who underwent revision surgery and thus were not able to determine whether the different surgical approaches might be associated with different revision rates, ${ }^{29}$ which have an impact on functional outcomes. We were unable to comment on the risk of instability associated with each surgical approach, either because patients who experienced instability were excluded (because they underwent revision surgery) or because our sample was too small. The question of how patients were selected for each approach leads to an important concern. The 7 surgeons involved in this study usually each perform a single surgical approach, depending on their personal opinions and their comfort level with the different approaches. It is possible that they may have switched to another approach for patients who had a particular anatomy or some other specific characteristic, but this is difficult to ascertain in a retrospective study. Nevertheless, apart from a slight difference in terms of mean age, the patients who underwent the 3 approaches had similar demographic characteristics, which reveals good homogeneity among the groups. Another limitation is the impact of adjacent joint arthritis and/or other joint replacement on patient-reported outcome measures. We tried to address this by controlling for the Charnley classification, which did not show differences among the 3 approaches. Moreover, even if we had controlled for the most important confounders using a multivariate analysis model, there would still have been some relevant cofounders that could potentially have led to a bias, such as smoking, socioeconomic status or femoral head diameter. However, we do not have any reason to think that these parameters might be unequally distributed among the 3 groups. Our study cohort represented $19.5 \%$ of the complete cohort. This level of compliance (in terms of percentage) in follow-up is comparable with that in the Swedish Hip Arthoplasty Register study: their loss to follow-up was greater than $80 \%$ after 1 year. ${ }^{26}$ The fact that not all patients have PROM scores was predetermined as in 2010 we instituted a protocol whereby 1 in 5 patients who returned their preoperative questionnaire would be asked to complete their PROMs at followup. Postoperative PROMs are, however, missing at random, and our statistical power was sufficient. The differences between the original and final groups were for physical health status (ASA class), age and preoperative scores on the WOMAC and HOOS instruments. Although the differences were statistically significant, they were not clinically relevant. The difference in age was only 2 years. The differences in WOMAC and HOOS scores were under the minimal detectable change of these instruments. ${ }^{5,6}$ Nevertheless, patients in the final sample tended to be healthier, as determined by ASA score. Finally, a greater percentage of patients in the anterior approach group (27.4\%) completed PROMs than patients 
in the posterior approach (16.6\%) and lateral approach $(17.2 \%)$ groups. Therefore, the results for patients in the anterior approach group are more representative than those of the other groups.

\section{Conclusion}

Our study provides valuable information about the significant benefits that the 3 most common surgical approaches to THR provide in regard to patient-reported outcomes at long-term follow-up. Further studies are needed to assess the role of implant design as well as prerehabilitation protocols in further optimizing recovery in both the short and long term.

Affiliations: From the Ottawa, Hospital, Ottawa, Ont. (Galmiche, Dobransky, Kim, Feibel, Gofton, Abdelbary, Beaulé); and the School of Rehabilitation, University of Ottawa, Ottawa, Ont. (Poitras).

Competing interests: W. Gofton has received personal fees from Zimmer Biomet and MicroPort outside the submitted work. P. Beaulé has received personal fees from MicroPort, MatOrtho, Zimmer Biomet, Medacta and Corin, a grant from Zimmer Biomet and research suport from DePuy Synthes (Johnson \& Johnson) outside the submitted work. No other competing interests were declared.

Contributors: S. Poitras, P. Kim, R. Feibel and W. Gofton designed the study. R. Galmiche, J. Dobransky, R. Feibel, W. Gofton, H. Abdelbary and P. Beaulé acquired the data, which R. Galmiche, S. Poitras, S. Dobransky, R. Feibel, W. Gofton and P. Beaulé analyzed. R. Galmiche, S. Poitras, J. Dobransky, Gofton and P. Beaulé wrote the article, which R. Galmiche, S. Poitras, J. Dobransky, P. Kim, R. Feibel, W. Gofton, H. Abdelbary and P. Beaulé critically reviewed. All authors approved the article for publication.

\section{References}

1. Learmonth ID, Young C, Rorabeck C. The operation of the century: total hip replacement. Lancet 2007;370:1508-19.

2. Chechik O, Khashan M, Lador R, et al. Surgical approach and prosthesis fixation in hip arthroplasty world wide. Arch Orthop Trauma Surg 2013;133:1595-600.

3. Carli AV, Poitras S, Clohisy JC, et al. Variation in use of postoperative precautions and equipment following total hip arthroplasty: a survey of the AAHKS and CAS membership. F Artbroplasty 2018;33:3201-5.

4. Kwon MS, Kuskowski M, Mulhall KJ, et al. Does surgical approach affect total hip arthroplasty dislocation rates? Clin Orthop Relat Res 2006;447:34-8.

5. Masonis JL, Bourne RB. Surgical approach, abductor function, and total hip arthroplasty dislocation. Clin Orthop Relat Res 2002;405:46-53.

6. Sariali ELP, Mamoudy P. Dislocation after total hip arthroplasty using Hueter anterior approach. 7 Arthroplasty 2008;23:266-72.

7. Fox AJ, Bedi A, Florian W, et al. Femoral neuropathy following total hip arthroplasty review and management guidelines. Acta Orthop Belg 2012;78:145-51.

8. Simmons C Jr, Izant TH, Rothman RH, et al. Femoral neuropathy following total hip arthroplasty: anatomic study, case reports, and literature review. F Arthroplasty 1991;6:S57-66.

9. Goulding K, Beaule PE, Kim PR, et al. Incidence of lateral femoral cutaneous nerve neuropraxia after anterior approach hip arthroplasty. Clin Orthop Relat Res 2010;468:2397-404.

10. Hendel D, Yasin M, Garti A, et al. Fracture of the greater trochanter during hip replacement. Acta Orthop Scand 2002;73:295-7.

11. Matta JM, Shahrdar C, Ferguson T. Single-incision anterior approach for total hip arthroplasty on an orthopaedic table. Clin Orthop Relat Res 2005;441:115-24.
12. Barrett WP, Turner SE, Leopold JP. Prospective randomized study of direct anterior vs postero-lateral approach for total hip arthroplasty. 7 Arthroplasty 2013;28:1634-8.

13. Alecci V, Valente M, Crucil M, et al. Comparison of primary total hip replacements performed with a direct anterior approach versus the standard lateral approach: perioperative findings. 7 Orthop Traumatol 2011;12:123-9.

14. Witzleb WC, Stephan L, Krummenauer F, et al. Short-term outcome after posterior versus lateral surgical approach for total hip arthroplasty — a randomized clinical trial. Eur 7 Med Res 2009;14:256-63.

15. Araújo P, Machado L, Cadavez D, et al. Evaluation of the function and quality of life after total hip arthroplasty by different approaches. Acta Med Port 2017;30:623-7.

16. Bedard NA, Callaghan JJ, Stefl MD, et al. Systematic review of literature of cemented femoral components: What is the durability at minimum 20 years followup? Clin Orthop Relat Res 2015;473:563-71.

17. Naylor JM, Hayen A, Davidson E, et al. Minimal detectable change for mobility and patient-reported tools in people with osteoarthritis awaiting arthroplasty. BMC Musculoskelet Disord 2014;15:235.

18. Quintana JM, Escobar A, Bilbao A, et al. Responsiveness and clinically important differences for the WOMAC and SF-36 after hip joint replacement. Osteoarthritis Cartilage 2005;13:1076-83.

19. Keggi KJ, Huo M, Zatorski L. Anterior approach to total hip replacement: surgical technique and clinical results of our first one thousand cases using non-cemented prostheses. Yale 7 Biol Med 1993;66:243-56.

20. Rorabeck CH, Bourne RB, Laupacis A, et al. A double-blind study of 250 cases comparing cemented with cementless total hip arthroplasty. Cost-effectiveness and its impact on health-related quality of life. Clin Orthop Relat Res 1994;298:156-64.

21. Lamontagne M, Beaulieu ML, Varin D, et al. Gait and motion analysis of the lower extremity after total hip arthroplasty: what the orthopedic surgeon should know. Orthop Clin North Am 2009;40:397-405.

22. Miller LE, Gondusky JS, Bhattacharyya S, et al. Does surgical approach affect outcomes in total hip arthroplasty through 90 days of follow-up? A systematic review with meta-analysis. 7 Arthroplasty 2018;33:1296-302.

23. Palan J, Beard DJ, Murray DW, et al. Which approach for total hip arthroplasty: anterolateral or posterior? Clin Orthop Relat Res 2009;467:473-7.

24. Restrepo C, Parvizi J, Pour AE, et al. Prospective randomized study of two surgical approaches for total hip arthroplasty. 7 Arthroplasty 2010;25:671-9.e1.

25. Smith AJ, Wylde V, Berstock JR, et al. Surgical approach and patient-reported outcomes after total hip replacement. Hip Int 2012;22:355-61.

26. Lindgren J, Wretenberg P, Kärrholm J, et al. Patient-reported outcome is influenced by surgical approach in total hip replacement: a study of the Swedish Hip Arthroplasty Register including 42233 patients. Bone foint F 2014;96:590-6.

27. Reichert JC, Volkmann MR, Koppmair M, et al. Comparative retrospective study of the direct anterior and transgluteal approaches for primary total hip arthroplasty. Int Orthop 2015;39:2309-13.

28. Meneghini RM, Pagnano MW, Trousdale RT, et al. Muscle damage during MIS total hip arthroplasty: Smith-Petersen versus posterior approach. Clin Orthop Relat Res 2006;453:293-8.

29. Lindgren V, Garellick G, Kärrholm J, et al. The type of surgical approach influences the risk of revision in total hip arthroplasty: a study from the Swedish Hip Arthroplasty Register of 90,662 total hip replacements with 3 different cemented prostheses. Acta Orthop 2012;83:559-65.

30. Meneghini RM, Smits SA, Swinford RR, et al. A randomized, prospective study of 3 minimally invasive surgical approaches in total hip arthroplasty: comprehensive gait analysis. F Arthroplasty 2008;23:68-73.

31. Lamontagne M, Varin D, Beaulé PE. Does the anterior approach for total hip arthroplasty better restore stair climbing gait mechanics? 7 Orthop Res 2011;29:1412-7. 
32. Pagnano MW, Trousdale RT, Meneghini RM, et al. Slower recovery after two-incision than mini-posterior-incision total hip arthroplasty: a randomized clinical trial. 7 Bone foin Surg Am 2008;90:1000-6.

33. Taunton MJ, Trousdale RT, Sierra RJ, et al. John Charnley Award: randomized clinical trial of direct anterior and miniposterior approach THA: Which provides better functional recovery? Clin Orthop Relat Res 2018;476:216-29.

34. Graves SC, Dropkin BM, Keeney BJ, et al. Does surgical approach affect patient-reported function after primary THA? Clin Orthop Relat Res 2016;474:971-81.

35. Queen RM, Appleton JS, Butler RJ, et al. Total hip arthroplasty surgical approach does not alter postoperative gait mechanics one year after surgery. PM R 2014;6:221-6.

36. Baker AS, Bitounis V. Abductor function after total hip replacement. An electromyographic and clinical review. 7 Bone foint Surg $\mathrm{Br}$ 1989;71:47-50.

37. Foucher KC. Gait abnormalities before and after total hip arthroplasty differ in men and women. 7 Biomech 2016;49:3582-6.

38. Foucher KC. Preoperative gait mechanics predict clinical response to total hip arthroplasty. 7 Orthop Res 2017;35:366-76.

39. Müller M, Tohtz S, Dewey M, et al. Muscle trauma in primary total hip arthroplasty depending on age, BMI, and surgical approach: minimally invasive anterolateral versus modified direct lateral approach. Orthopade 2011;40:217-23.
40. Liu W, Wahafu T, Cheng M, et al. The influence of obesity on primary total hip arthroplasty outcomes: a meta-analysis of prospective cohort studies. Orthop Traumatol Surg Res 2015;101:289-96.

41. Müller M, Tohtz S, Dewey M, et al. Age-related appearance of muscle trauma in primary total hip arthroplasty and the benefit of a minimally invasive approach for patients older than 70 years. Int Orthop 2011;35:165-71.

42. Preininger B, Schmorl K, von Roth P, et al. The sex specificity of hip-joint muscles offers an explanation for better results in men after total hip arthroplasty. Int Orthop 2012;36:1143-8.

43. Çatma FM, Öztürk A, Ünlü S, et al. Posterior hip approach yields better functional results vis-à-vis anterolateral approach in total hip arthroplasty for patients with severe hip dysplasia: a prospective randomized controlled clinical study. F Orthop Surg 2017;25:2309499017717179.

44. Wamper KE, Sierevelt IN, Poolman RW, et al. The Harris hip score: Do ceiling effects limit its usefulness in orthopedics? A systematic review. Acta Orthop 2010;81:703-7.

45. Lamontagne M, Beaulieu ML, Varin D, et al. Lower-limb joint mechanics after total hip arthroplasty during sitting and standing tasks. 7 Orthop Res 2012;30:1611-7. 